\title{
Morphological Measurements of Knee Joints in Mongolian Population
}

\author{
Naranbat Lkhagvasuren1, Erdenebileg Avirmed1, Batsukh Ombogo1, Battulga Khaltar1, \\ Zolbayar Baasanjav1, Otgonsaikhan Nomkhoidorj', Munkhbaatar Dagvasumberel2, \\ Puntsag Chultemsuren ${ }^{3}$, Avirmed Amgalanbaatar ${ }^{4}$, Munkhbayarlakh Sonomjamts ${ }^{5}$
}

\footnotetext{
${ }^{1}$ Department of Orthopeadic, School of Medicine, Mongolian National University of Medical Sciences, Ulaanbaatar, Mongolia ${ }^{2}$ Department of Radiology, School of Medicine, Mongolian National University of Medical Sciences, Ulaanbaatar, Mongolia ${ }^{3}$ Department of General Surgery, School of Medicine, Mongolian National University of Medical Sciences, Ulaanbaatar, Mongolia ${ }^{4}$ Department of Anatomy, School of Medicine, Mongolian National University of Medical Sciences, Ulaanbaatar, Mongolia ${ }^{5}$ Department of Physiology, School of Medicine, Mongolian National University of Medical Sciences, Ulaanbaatar, Mongolia Email: naranbat@mnums.edu.mn
}

How to cite this paper: Lkhagvasuren, N., Avirmed, E., Ombogo, B., Khaltar, B., Baasanjav, Z., Nomkhoidorj, O., Dagvasumberel, M., Chultemsuren, P., Amgalanbaatar, A. and Sonomjamts, M. (2018) Morphological Measurements of Knee Joints in Mongolian Population. Open Journal of Applied Sciences, 8, 619-626. https://doi.org/10.4236/ojapps.2018.812050

Received: December 10, 2018 Accepted: December 26, 2018 Published: December 29, 2018

Copyright (c) 2018 by authors and Scientific Research Publishing Inc. This work is licensed under the Creative Commons Attribution International License (CC BY 4.0).

http://creativecommons.org/licenses/by/4.0/ (c) (†) Open Access

\begin{abstract}
Objective: This study was aimed to determine anthropometric measurements of knee joint among healthy Mongolian population and identify FML (Femur Medial Lateral), TML (Tibia Media Lateral), PML (Patella Medial Lateral), PAP (Patella Anterior Posterior), FAP (Femur Anterior Posterior) and TAP (Tibia Anterior Posterior). Methods: This cross-sectional study included 100 participants. We measured femoral, tibial and patellar dimensions using X-ray. Result: A total of 100 participants (44 male, 56 female participants) enrolled in this study. Age was ranged $20-59$ and average age was $38 \pm 9$. Average FAP was $70.6 \pm 1.22 \mathrm{~mm}$ in male and $66.9 \pm 3.93 \mathrm{~mm}$ in female. Average TML in male was $85.6 \pm 1.27 \mathrm{~mm}$ and $79.1 \pm 0.8 \mathrm{~mm}$ in female. Average TAP was $60.1 \pm 4.87 \mathrm{~mm}$ in male and $55.7 \pm 4.96$ in female. Average PAP was $22.5 \pm 2.83 \mathrm{~mm}$ in male and $23.8 \pm 2.43 \mathrm{~mm}$ in female. Average PML was 50.2 $\pm 1.45 \mathrm{~mm}$ in male and $46.8 \pm 4.09 \mathrm{~mm}$ in female. Knee anthropometric measurements were statistically different in gender $(\mathrm{P}<0.0002)$. Conclusion: Participants average FML was statistically lower than Asian and European people and FAP was statistically higher than them.
\end{abstract}

\section{Keywords}

FAP, TML, TAP, PML, PAP, Osteoarthritis

\section{Introduction}

According to the WHO study in 1998-2015, the prevalence of Osteoarthritis 
(OA) is increasing $10 \%$ - $15 \%$ year by year. Related to OA, burden of musculoskeletal disability is increasing as well [1].

In 1970, total knee joint arthroplasty guideline was created in USA. In that time, ligaments were kept and replace joint surface was developed. In 1974, first patellar replacement was introduced as well as joint surface replacing. After that, scientists developed the method of installing prosthesis with bone-cement and retaining anterior and posterior cruciate ligaments. In modern days, there are more than 19 companies which are producing 3 types of joint prosthesis [2].

Yue Bing et al. studied about differences of knee anthropometry between Chinese and white men and women. The result of this study showed that anthropometric references of Chinese knee were generally smaller than white knees [3].

However, another study showed that knee anthropometric references of Chinese, Thailand and Japanese people are similar [4].

Yohei Kawahara et al. studied anthropometric measurements of femur and tibia among East Asian, Central Asian and white population. The study reported that FML of white and East Asian people was significantly lower. Even though, tibial surface of white people was greater than black people. They emphasized that patient-specific designed prosthesis based on individual anatomical reference can reduce the surgical complication, enhance the functional recovery and quality of life [5].

Furthermore, knee replacement surgery has been increasing as well as its demands. Therefore, manufacturing companies are trying to produce knee prosthesis for such nationalities based on their knee anthropometric measurements.

\section{Materials and Methods}

\subsection{Study Design and Sampling}

In this cross-sectional study, randomly accessed 20 - 59 aged, 100 participants included. Participant involved the study between 2017-2018. Total number of participants identified by sample sizing theory.

We measured FML (Femur Medial Lateral), TML (Tibia Media Lateral), PML (Patella Medial Lateral), PAP (Patella Anterior Posterior), FAP (Femur Anterior Posterior) and TAP (Tibia Anterior Posterior). Lower extremities injuries, surgery, no history of injury, and congenital development defects were included in exclusion criteria.

Inclusion criteria-healthy adults.

\subsection{Measurement Technic}

We used Smart Digital Radiography from Korean Samsung brand for knee X-ray. Knee X-ray included 2 position of images which are anterior-posterior and lateral. Participant is supine on the table with the knee extended and ankle joint in contact with the table. X-ray detector was located in $60 \mathrm{~cm}$ distance from patella and perpendicularly reflected.

Totally, 14 dimensions measured and DICOM program used for measuring (dimensions demonstrated by $\mathrm{mm}$ ) (Figure 1, Figure 2). 


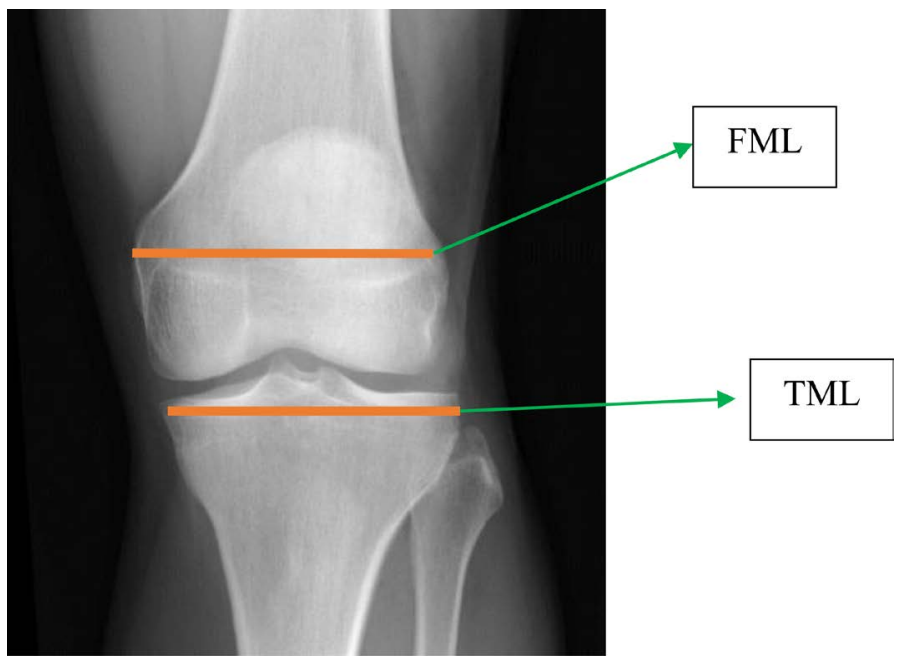

Figure 1. Dimensions of FML and TML X-ray (Femur medial lateral (FML) Tibia medial lateral (TML)).

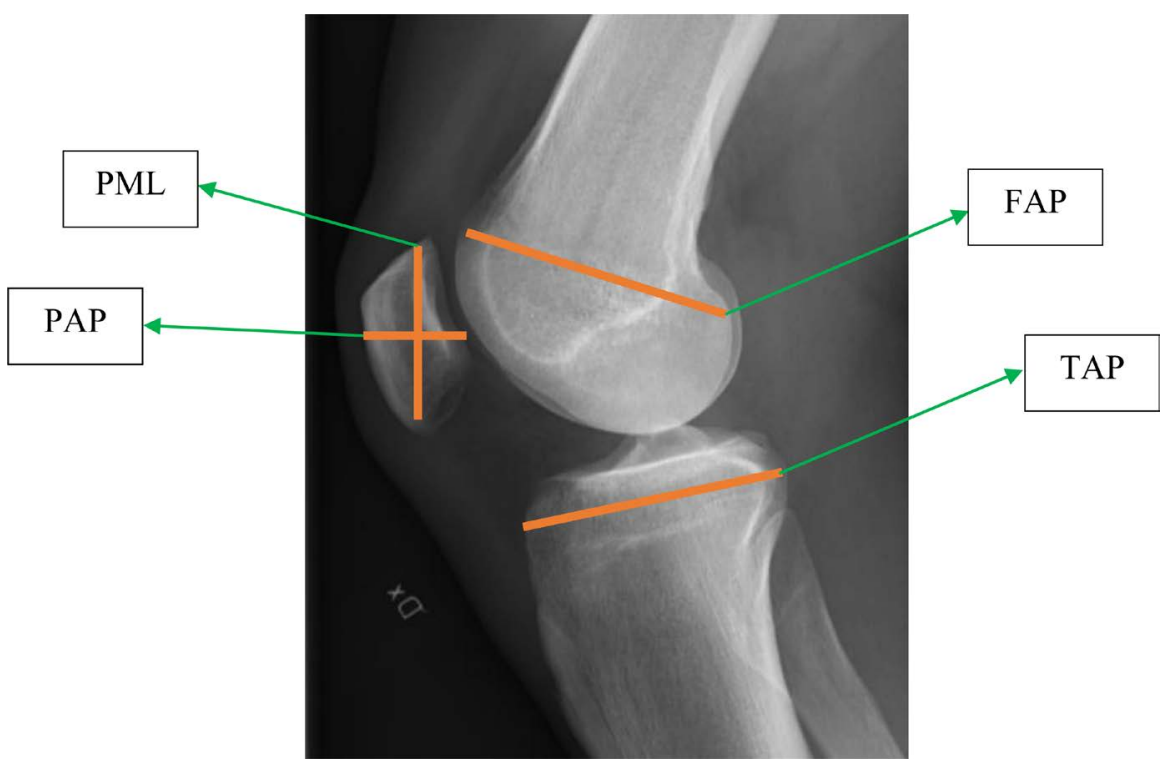

Figure 2. Tibial and patellar dimensions' X-ray (Femur anterior-posterior (FAP), tibia anterior-posterior (TAP), Patella medial lateral PML, Patella anterior-posterior (PAP)).

\subsection{Statistical Analysis}

All statistical analysis made with STATA 20 program. We've calculated arithmetic average and standard deviation with normal distribution. However, we calculated median, first and second quartile (P25, P75) with skewed distribution using overview statistic.

Independent $\mathrm{t}$-test used for examine difference between men and women knee joint anthropometric measurements when normal distribution. When it has non-normal distribution, Wilcoxon rank-sum (Mann-Whitney) test used. $\mathrm{P}$ value is less than 0.05 is considered as statistically significant. Multiple linear regression was performed to examine the association of FML, FAP, TML, TAP and gender, age, height and BMI. 


\subsection{Ethical Statement}

Ethical approval for this study was acquired from the Research Ethics Committee of the Mongolian National University of Medical Sciences on $23^{\text {th }}$ October, 2016 with $16^{\text {th }}$ order. Before data collection, the participants signed a written, informed consent.

\section{Result}

A total of 100 participants, 44 male, 56 female participants enrolled in this study. Age was ranged 20 - 59 and average age was $38 \pm 9$ (Table 1).

For male, average weight was $63 \pm 13 \mathrm{~kg}$, height was $168 \pm 10 \mathrm{~cm}$ and average BMI was $22 \pm 5.17 \mathrm{~kg} / \mathrm{m}^{2}$. For female average weight was $65 \pm 12 \mathrm{~kg}$, height was $167 \pm 10 \mathrm{~cm}$ and average BMI was $23 \pm 5.3 \mathrm{~kg} / \mathrm{m}^{2}$. Average FML was $62.6 \pm 7.45$ $\mathrm{mm}$ in male and $59.1 \pm 5.79 \mathrm{~mm}$ in female participants. Average FAP was $70.6 \pm$ $1.22 \mathrm{~mm}$ in male and $66.9 \pm 3.93 \mathrm{~mm}$ in female. Average TML in male was 85.6 $\pm 1.27 \mathrm{~mm}$ and $79.1 \pm 0.8$ was in female. Average TAP was $60.1 \pm 4.87 \mathrm{~mm}$ in male and $55.7 \pm 4.96$ in female. Average PAP was $22.5 \pm 2.83 \mathrm{~mm}$ in male and $23.8 \pm 2.43 \mathrm{~mm}$ in female. Average PML was 50.2 \pm 1.45 in male and $46.8 \pm 4.09$ $\mathrm{mm}$ in female (Figure 3, Figure 4).

Independent $t$-test used for examine difference between male and female FML $(\mathrm{P}<0.0096)$, FAP $(\mathrm{P}<0.03)$, TML $(\mathrm{P}<0.001)$, TAP $(\mathrm{P}<0.0001)$ and it was statistically significant. Moreover, knee anthropometric measurements were statistically correlated with height.

Knee anthropometric measurements were statistically different in gender $(\mathrm{P}<$ $0.0002)$.

Wilcoxon rank-sum (Mann-Whitney) test used to identify average patellar Table 1. Measurements of FML and FAP.

\begin{tabular}{cccccc} 
& & & & & \\
& Male M \pm SD & Female $\mathrm{M} \pm \mathrm{SD}$ & 95 C & P value \\
\hline Age & $38.6 \pm 9.6$ & $38.6 \pm 9.7$ & 3.042435 & 3.354915 & $0.002^{\dagger}$ \\
Height & $168.5 \pm 10.7 \mathrm{~mm}$ & $167.5 \pm 11.6 \mathrm{~mm}$ & 1.686118 & 1.756987 & $0.001^{\dagger}$ \\
Weight & $63.3 \pm 12.9 \mathrm{~kg}$ & $65.1 \pm 12.7 \mathrm{~kg}$ & 9.306745 & 9.36573 & $0.05^{\dagger}$ \\
BMI & $22.5 \pm 5.1$ & $23.5 \pm 5.6$ & 6.883162 & 9.569714 & $0.03^{\dagger}$ \\
FML & $62.6 \pm 7.45 \mathrm{~mm}$ & $59.1 \pm 5.79 \mathrm{~mm}$ & 6.042435 & 6.495747 & $0.0096^{\dagger}$ \\
FAP & $70.6 \pm 1.22 \mathrm{~mm}$ & $66.9 \pm 3.93 \mathrm{~mm}$ & 6.686118 & 6.074344 & $0.03^{\dagger}$ \\
TML & $85.6 \pm 1.27 \mathrm{~mm}$ & $79.1 \pm 0.8 \mathrm{~mm}$ & 5.859346 & 6.159258 & $0.001^{\dagger}$ \\
TAP & $60.1 \pm 4.87 \mathrm{~mm}$ & $55.7 \pm 4.96 \mathrm{~mm}$ & 5.559346 & 5.861487 & $0.0001^{\dagger}$ \\
PML & $50.2 \pm 1.45 \mathrm{~mm}$ & $46.8 \pm 4.09 \mathrm{~mm}$ & 4.883162 & 4.896584 & $0.002^{\dagger}$ \\
PAP & $22.5 \pm 2.83 \mathrm{~mm}$ & $23.8 \pm 2.43 \mathrm{~mm}$ & 4.044612 & 4.569723 & $0.03^{\ddagger}$ \\
\hline
\end{tabular}

'Independent t-test, "Wilcoxon rank-sum (Mann-Whitney) test, Femur medial lateral (FML), femur anterior-posterior (FAP), tibia medial lateral (TML), tibia anterior-posterior (TAP), patella medial lateral (PML), patella anterior-posterior (PAP). 


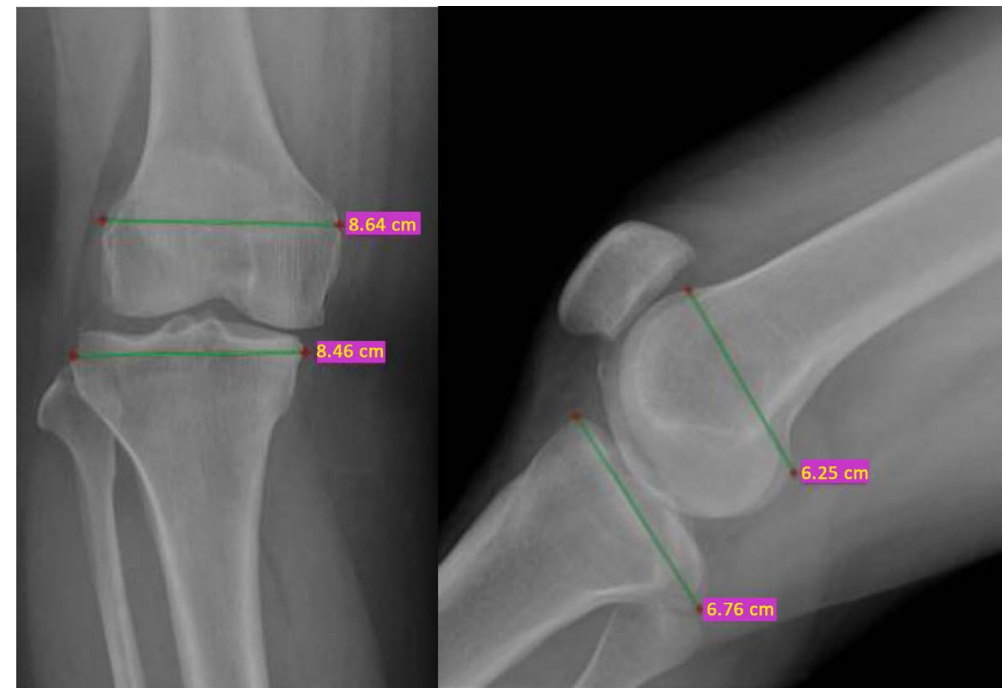

Figure 3. Anterior-posterior and lateral image of knee joint X-ray (FML-86.4 mm, TML-84.6 mm, FAP-62.5 mm, TAP-67.6 mm).

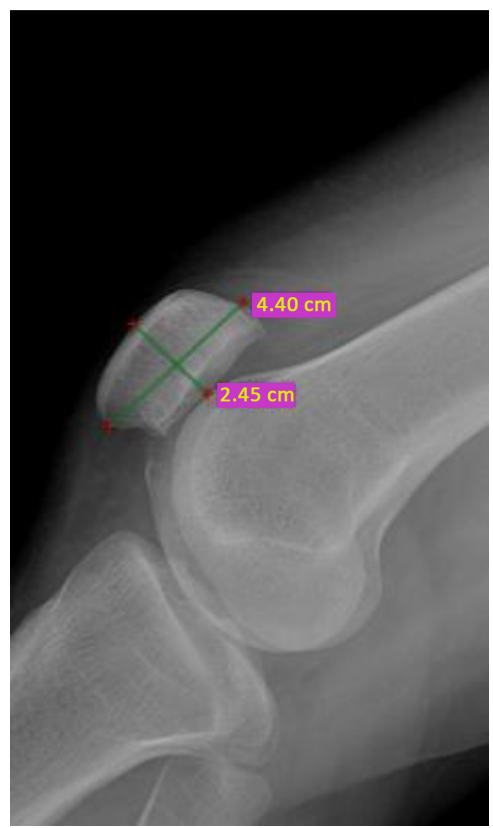

Figure 4. Lateral image of patellar X-ray (PML-44 mm, PAP-24.5 mm).

dimensions of male and female participants. As a result of the measurements, there was statistically significant difference in male and female patella $(\mathrm{P}<$ $0.002)$.

\section{Discussion}

In worldwide, the average life expectancy is increasing. Related with high life expectancy, obesity and lack of exercise are increasing as well. Moreover, it results enhancing of knee joint diseases. Therefore, case of total knee arthroplasty is rising. Thus, manufacturing companies need to produce knee prosthesis with specific morphologic for every nationality. In 1970, knee prosthesis produced in 
USA based on Western Europe anthropometric reference. However, Asia, specifically, Eastern Asian people need to have specific knee prosthesis due to high incidence of knee joint disease [6].

Fitted or adjusted knee prosthesis with bone for individual and long term stability is significant for successful knee arthroplasty. In order to improve the efficacy of surgery, manufacturing companies advocated to produce knee prosthesis or implants for countries in worldwide and nationalities' anatomical feature [7].

Researchers Hussain and Fitdriyah Kadir et al. studied FML and FAP among 100 Malaysian people. Malaysian male FML was $74.1 \pm 3.52 \mathrm{~mm}$ and female FML was $64.2 \pm 3.74 \mathrm{~mm}$. However, Mongolian male FML was $62.6 \pm 7.45$ and female FML was $59.1 \pm 5.79 \mathrm{~mm}$ and it was statistically significant $[8](\mathrm{P}<$ 0.009).

Korean researchers $\mathrm{Ha}, \mathrm{CW} \mathrm{Na}$ et al. studied FML and FAP among $100 \mathrm{Ko}-$ rean people. As a result of study, Korean male FML was $74.8 \pm 1.52 \mathrm{~mm}$ and female was $68.2 \pm 1.24 \mathrm{~mm}$. In the other hand, Mongolian male FML was $62.6 \pm$ 7.45 and female FML was $59.1 \pm 5.79 \mathrm{~mm}$ and it was statistically significant.

Moreover, Korean male FAP was $66.3 \pm 8.14 \mathrm{~mm}$ and female FAP was $60.8 \pm$ $3.41 \mathrm{~mm}$. Mongolian average male FAP was $70.6 \pm 1.22$ and female FAP was $66.9 \pm 3.93 \mathrm{~mm}$ and it was statistically significant $[9](\mathrm{P}<0.01)$.

Chaichankul and Pibul measured Thailand people's FAP and FML. As a result of this measurement, Thailand male FML was $71.5 \pm 3.73 \mathrm{~mm}$ and female FML was $59.4 \pm 3.74 \mathrm{~mm}$ and it was statistically significant $[5](\mathrm{P}<0.001)$.

In order to find appropriate size of knee prosthesis, normal knee anthropometric measurements need to be strongly considered. 3D CT scan used for measuring femoral and tibial dimensions [10] (Table 2).

Mahmoud A and Hafez identified FML and FAP of Arabian people. Furthermore, Arabian male FML was $78.6 \pm 7.51 \mathrm{~mm}$, and female FML was $75.8 \pm 5.41$ mm. However, Mongolian male FML was $62.6 \pm 7.45$ and female FML was 59.1

Table 2. Comparisons of FML and FAP (mm).

\begin{tabular}{cccc}
\hline & & FML $(\mathrm{M} \pm \mathrm{SD})$ & FAP $(\mathrm{M} \pm \mathrm{SD})$ \\
\hline \multirow{2}{*}{ Mongolia } & Male & $62.6 \pm 7.45$ & $70.6 \pm 1.22$ \\
& Female & $59.1 \pm 5.79$ & $66.9 \pm 3.93$ \\
China [8] & Male & $74.2 \pm 2.91$ & $66.2 \pm 2.41$ \\
& Female & $66.2 \pm 3.14$ & $61.6 \pm 2.71$ \\
India [6] & Male & $69.3 \pm 3.12$ & $61.2 \pm 3.74$ \\
& Female & $61.5 \pm 3.17$ & $54.5 \pm 1.96$ \\
Arabic [5] & Male & $78.6 \pm 7.51$ & $78.3 \pm 4.63$ \\
& Female & $75.8 \pm 5.41$ & $67.8 \pm 4.91$ \\
America [6] & Male & $85.7 \pm 4.76$ & $67.4 \pm 3.14$ \\
& Female & $75.8 \pm 2.34$ & $58.7 \pm 4.28$
\end{tabular}


$\pm 5.79 \mathrm{~mm}$.

Moreover, Arabian male FAP was $78.3 \pm 4.63 \mathrm{~mm}$ but in our study, Mongolian male FAP was $70.6 \pm 1.22 \mathrm{~mm}$ and it was statistically lower than Arabian people. However, there was statistic difference between Arabian female FAP 67.8 $\pm 4.91 \mathrm{~mm}$ and Mongolian female FAP $66.9 \pm 3.93 \mathrm{~mm}$.

Reducing or cutting knee prosthesis and adjusting with surface size is decreasing the complication and enhancing the quality of life. Not appropriate size of knee prosthesis such as oversized or small size makes instability, constant pain and raises the surgical complications [11].

Therefore, identifying knee joint anthropometric measurements of countries and nationalities is one of the major issues of manufacturing companies. Moreover, it will be beneficial for both health care and financial.

As a result of our study, Mongolian people knee joint, specifically, FML and FAP was statistically and significantly different than Asian and European people. Also, Asian average FAP was statistically greater.

Our study has following limitations. First, we used 2D dimensions related to financial situation and other issues which are save time and have less pain and stress for the participants. Second, our sample size was small which cannot represent whole nationality.

However, we aimed to continue our study in future. We will use 3D dimensions with help of MRI and cover more participants which can represents nationality.

\section{Conclusions}

1) Participants' average FML was statistically lower than Asian and European people and FAP was statistically higher than them.

2) Participants' average FML in male was $62.6 \pm 7.45 \mathrm{~mm}$, in female was 59.1 $\pm 5.97 \mathrm{~mm}$ and average FAP in male was $70.6 \pm 1.22 \mathrm{~mm}$ and in female was 66.9 $\pm 3.93 \mathrm{~mm}$.

3) Participants' average TML in male was $85.6 \pm 1.27 \mathrm{~mm}$, in female was 79.1 $\pm 0.8 \mathrm{~mm}$ and average TAP in male was $60.1 \pm 4.87 \mathrm{~mm}$ and in female was 55.7 $\pm 4.96 \mathrm{~mm}$.

4) Participants' average PML in male was $50.2 \pm 1.45 \mathrm{~mm}$, in female was 46.8 $\pm 4.08 \mathrm{~mm}$ and average PAP in male was $22.5 \pm 2.83 \mathrm{~mm}$ and in female was 23.8 $\pm 2.43 \mathrm{~mm}$.

\section{Conflicts of Interest}

The authors declare no conflicts of interest regarding the publication of this paper.

\section{References}

[1] Kim, T., Phillips, M., Bhandari, M., Watson, J. and Malhotra, R. (2017) What Differences in Morphologic Features of the Knee Exist among Patients of Various Races? A Systematic Review. Clinical Orthopaedics and Related Research, 475, 170-182. 
https://doi.org/10.1007/s11999-016-5097-4

[2] Karade, V. and Ravi, B. (2014) Analysis on Anatomical References to Assess the Coronal Alignment of Tibial and Femoral Cuts in Mega Prosthetic Knee Replacement. Journal of Orthopaedics and Traumatology, 15, 87-93.

https://doi.org/10.1007/s10195-013-0277-4

[3] Yue, B., Varadarajan, K.M., Ai, S., Tang, T., Rubash, H.E. and Li, G. (2011) Differences of Knee Anthropometry between Chinese and White Men and Women. The Journal of Arthroplasty, 26, 124-130. https://doi.org/10.1016/j.arth.2009.11.020

[4] Chaichankul, C., Tanavalee, A. and Itiravivong, P. (2011) Anthropometric Measurements of Knee Joints in Thai Population: Correlation to the Sizing of Current Knee Prostheses. The Knee, 18, 5-10. https://doi.org/10.1016/j.knee.2009.12.005

[5] Haruta, Y., Kawahara, S., Tsuchimochi, K., Hamasaki, A. and Hara, T. (2018) Deviation of Femoral Intramedullary Alignment Rod Influences Coronal and Sagittal Alignment during Total Knee Arthroplasty. The Knee, 25, 644-659. https://doi.org/10.1016/j.knee.2018.04.011

[6] Loures, F.B., Góes, R.Fd.A., Palma, I.Md., Labronici, P.J., Granjeiro, J.M. and Olej, B. (2016) Anthropometric Study of the Knee and Its Correlation with the Size of Three Implants Available for Arthroplasty. Revista brasileira de ortopedia, 51, 282-289. https://doi.org/10.1016/j.rbo.2015.07.003

[7] Neander, I. (2018) Jürgen von Hehn und Csaba János Kenez (Hrsg.): Reval und die baltischen Länder. Zeitschrift für Ostforschung, 30, 589-593.

[8] Hussain, F., Kadir, A., Rafiq, M., et al. (2013) Anthropometric Measurements of the Human Distal Femur: A Study of the Adult Malay Population. BioMed Research International, 2013, Article ID: 175056. https://doi.org/10.1155/2013/175056

[9] Ha, C. and Na, S. (2012) The Correctness of Fit of Current Total Knee Prostheses Compared with Intra-Operative Anthropometric Measurements in Korean Knees. The Journal of Bone and Joint Surgery British Volume, 94, 638-641. https://doi.org/10.1302/0301-620X.94B5.28824

[10] Zhang, Y., Xu, J., Ruan, Y.C., et al. (2016) Implant-Derived Magnesium Induces Local Neuronal Production of CGRP to Improve Bone-Fracture Healing in Rats. Nature Medicine, 22, 1160. https://doi.org/10.1038/nm.4162

[11] Nanci, A. (2017) Ten Cate's Oral Histology-E-Book: Development, Structure, and Function. Elsevier Health Sciences, Amsterdam. 